\title{
Choriocarcinoma following scar pregnancy: a case report
}

\author{
Sreelatha Sumangala ${ }^{1}$, Manjula Madhavan Pillai ${ }^{1}$, Nirmala Chellamma ${ }^{1}$, Laila Raji ${ }^{2}$
}

\author{
${ }^{1}$ Department of Obstetrics and Gynaecology, Sree Avittom Thirunal Hospital, Government Medical College, \\ Thiruvananthapuram, Kerala, India \\ ${ }^{2}$ Department of Pathology, Government Medical College, Thiruvananthapuram, Kerala, India
}

Received: 12 October 2016

Accepted: 07 November 2016

\section{*Correspondence:}

Dr. Sreelatha Sumangala,

E-mail: ssreelatha28@yahoo.com

Copyright: (c) the author(s), publisher and licensee Medip Academy. This is an open-access article distributed under the terms of the Creative Commons Attribution Non-Commercial License, which permits unrestricted non-commercial use, distribution, and reproduction in any medium, provided the original work is properly cited.

\begin{abstract}
Choriocarcinoma following scar pregnancy is a very rare entity. Here we present such a unique case. The index pregnancy was a sterilization failure which developed in the scar of previous caesarean. The scar pregnancy was evacuated through a hysterotomy incision and she was re sterilized. The histopathology report of the evacuated products showed normal villi. Two and a half months later she presented with bleeding per vaginum. Her beta HCG was raised and she had a vascular mass in the lower uterine myometrium. Gestational trophoblastic neoplasia was suspected and three courses of methotrexate folinic acid regime were administered. But the fall in beta HCG was inappropriate. She had no desire for future fertility and was not willing for combination chemo therapy. So hysterectomy was done. Histopathology revealed choriocarcinoma. Chest X-ray was apparently normal but CT chest showed micro metastasis. She had three courses of EMA-CO and is under follow up. She is asymptomatic and her beta HCG is less than $5 \mathrm{IU} / 1$.
\end{abstract}

Keywords: Choriocarcinoma, Scar pregnancy, Sterilization failure

\section{INTRODUCTION}

Choriocarcinoma is the most malignant form of gestational trophoblastic neoplasia. The true incidence of choriocarcinoma is difficult to compute as histopathological correlation is not always available and not essential to plan treatment. The approximate incidence is $1 / 40000$ to $9 / 40000$ pregnancies. ${ }^{1}$ The usual site of primary choriocarcinoma is the uterine body. Ectopic sites have been reported. ${ }^{2,3}$ The incidence of Caesarean scar pregnancy is $1 / 1800$ but increasing due to the rising caesarean section rate. ${ }^{4}$ Choriocarcinoma developing in the lower uterus following a scar pregnancy is extremely rare. $^{5-8}$ Here is a case of choriocarcinoma which developed in lower uterus within five months of removal of a scar pregnancy.

\section{CASE REPORT}

A 29 year old third gravida with previous two caesarean section, last caesarean section with concurrent sterilisation done two and a half years back, presented to a local hospital with six weeks amenorrhoea and bleeding per vaginum. Her beta HCG was 2286 IU/L. Evacuation attempted at local hospital and due to a suspicion of scar pregnancy an ultra-sonogram was done which showed retained products in the scar area. Methotrexate $75 \mathrm{mg}$ was given intramuscularly. On day 10 of evacuation beta HCG was 69.61 but on day 20 it rose to $1720 \mathrm{IU} / \mathrm{L}$. Ultra sonogram showed a heterogeneous lesion at the scar site of $1.4 * 1.3 \mathrm{~cm}$ with increased vascularity. Four days later she underwent a laparotomy in our centre. Uterus was opened through the lower segment and adherent products of conception removed from there. The endometrial cavity was free. She was resterilised. The histopathology 
showed normal villi (Figure 1). On seventh day of surgery beta HCG was $40.4 \mathrm{IU} / \mathrm{L}$ and she was discharged.

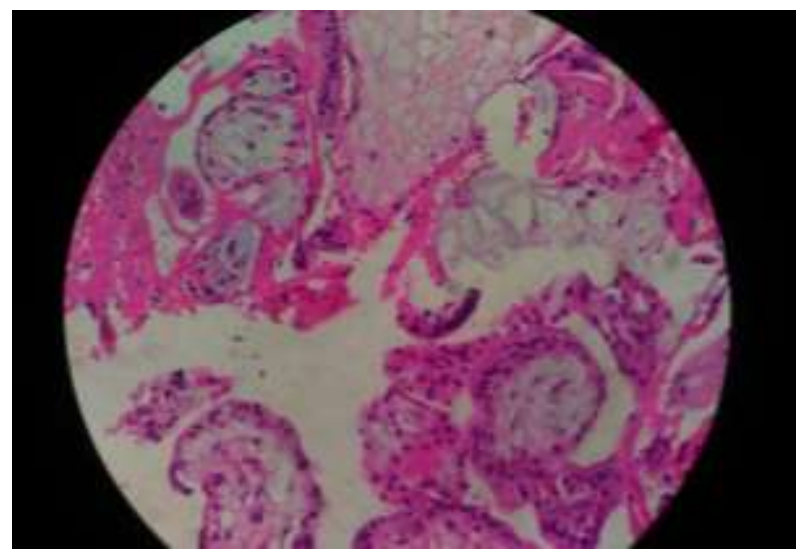

Figure 1: Histopathology slide of the products of conception evacuated through hysterotomy. Shows chorionic villi lined by inner cytotrophoblast and outer syncytial trophoblast.

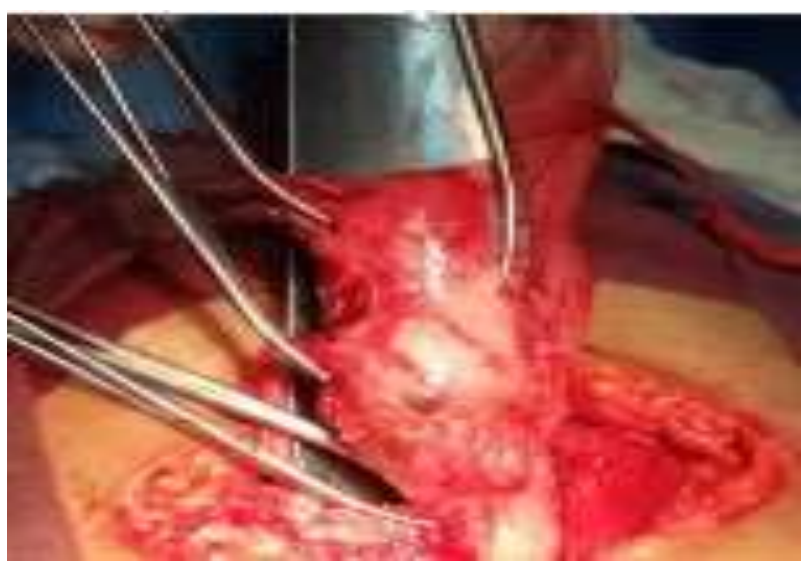

Figure 2: Lower part of the uterus enlarged with bluish bulges.

Ten weeks following surgery she presented with bleeding per vaginum and the $\beta$ HCG was 50998 IU/L .Ultra sonogram revealed irregular multiple cystic masses with vascularity in the lower uterine myometrium. MRI revealed a heterogeneous mass lesion in the right anterolateral wall of lower uterus. With a provisional diagnosis of gestational trophoblastic neoplasia she was started on methotrexate - folinic acid regime. After 3 courses, her beta HCG did not regress appropriately and USS showed that the lesion was almost reaching the serosa. Sensing methotrexate failure, options were discussed. As she had no desire for future fertility and was not willing for combination chemotherapy, hysterectomy was done. At laparotomy the fundus and body of uterus appeared normal, the lower segment was enlarged and soft, the right anterolateral portion was bulging with a mass reaching up to the serosa and almost breaching it with a yellowish hue. Ovaries were normal and retained. Cervix was normal (Figure 2).
The histopathology was choriocarcinoma. (Figure 3 and Figure 4).CT chest showed micro metastasis. FIGO stage was III and risk score was 7. She was started on EMA$\mathrm{CO}$ regime. After two courses her HCG was $4 \mathrm{IU} / \mathrm{L}$. She had a third course and is on follow up.

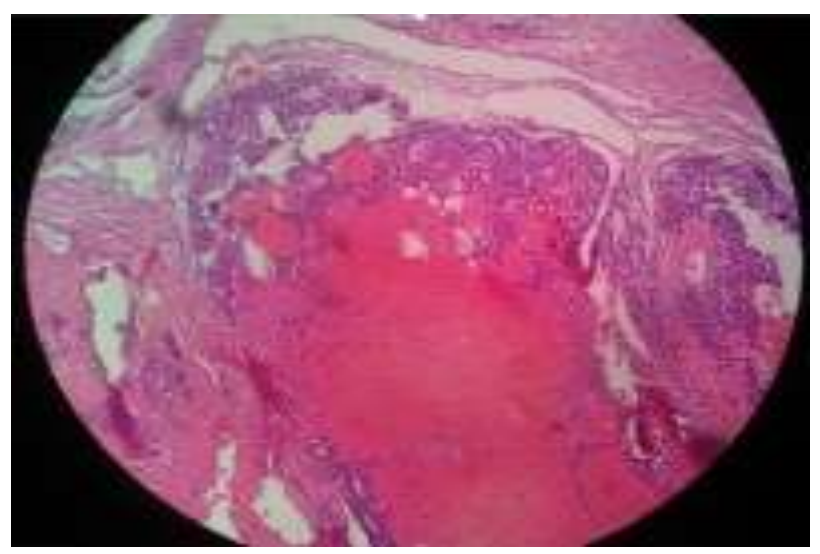

Figure 3: Choriocarcinoma low power view extensive haemorrhage and necrosis.

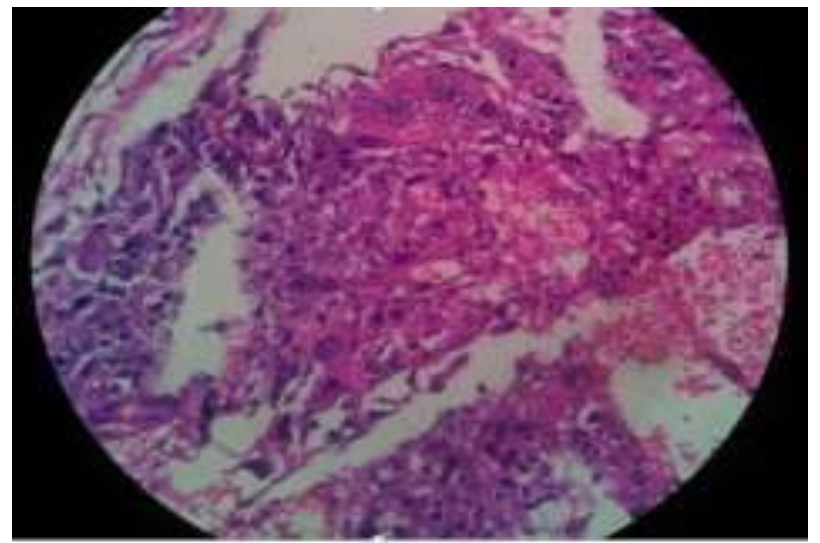

Figure 4: Choriocarcinoma high power view - sheets of cytotrophoblast with marked atypia intermixed with cells in syncytial pattern and absent chorionic villi.

\section{DISCUSSION}

Scar pregnancy is a rare event. The incidence is about 1/ 1800 to $1 / 2000$. $^{4}$ The mainstay of diagnosis is sonogram where the gestational sac is seen in the fibrous tissue of scar. The uterine cavity and cervical canal is empty. The anterior myometrium is thin and unhealthy with a profuse blood flow. The diagnosis of scar pregnancy may be missed unless carefully looked for, particularly so in cases of failing pregnancy. Excessive bleeding or difficulty during evacuation may provide a clue to the diagnosis as is evident in our case report. Different modalities of management are available but there is no consensus as to the best one. ${ }^{5-8}$ Here failed evacuation was followed by a dose of systemic methotrexate. As HCG was rising scar ectopic was evacuated through a hysterotomy. The pregnancy was non molar as evidenced 
by the normal villi in the histopathology report. The HCG decline was also appropriate. So she was discharged.

Association of choriocarcinoma and scar pregnancy is extremely rare. Literature review showed four cases of malignant gestational trophoblastic neoplasia in a scar. ${ }^{5-8}$ The case reported by $\mathrm{T}$ Bekci et al was choriocarcinoma following a molar pregnancy in a scar for which hysterectomy was done. ${ }^{8}$ The case report by Antonella V et al was a partial molar scar pregnancy which evolved into an invasive mole. ${ }^{6}$ It responded to methotrexate. The case reported by Qian ZD et al was a choriocarcinoma in the scar which was mistakenly diagnosed as scar pregnancy. ${ }^{5}$ She had a history of abortion four months prior. In that case after intra-arterial injection of methotrexate and uterine artery embolization, evacuation of products and packing of the deficient anterior uterine wall was done. Histopathology revealed choriocarcinoma and was treated with eight courses of EMA/CO regime. The case reported by Sherer DM et al was spontaneous uterine perforation of the uterus following caesarean scar choriocarcinoma. $^{7}$

In our case, the index pregnancy was non molar and nothing warranted a close follow up. She had an episode of bleeding four weeks after surgery which she assumed to be a normal cycle. When she presented after 10 weeks with prolonged bleeding, her HCG was 50,998 IU/L. In the case reported by Qian et al, HCG was above three lakhs. ${ }^{5}$ Here it was not very high to befit a choriocarcinoma but cases of choriocarcinoma with very low values of HCG have been reported. ${ }^{10,11}$ After a nonmolar pregnancy when there is a rising HCG the chance is more for a choriocarcinoma than other forms of trophoblastic neoplasia. Methotrexate resistance should also point to the possibility of choriocarcinoma. ${ }^{12}$

\section{CONCLUSION}

Even though choriocarcinoma is rare after a scar pregnancy, it can occur. If not diagnosed and treated promptly, it can lead to dangerous consequences.

Funding: No funding sources

Conflict of interest: None declared

Ethical approval: Informed written consent was obtained from the patient for publication of her case and the pictures. The identity of the patient is not disclosed

\section{REFERENCES}

1. Hextan YSN, Seckl MJ, Berkowitz RS, Xiang Y, Golfier F, Sekharan PK, et al. Update on the diagnosis and management of gestational trophoblastic disease. International Journal of Gynecology and Obstetrics. 2015;131:S123-6.

2. Mitrovic SL, Arsenijevic PS, Kljakic D, Djuric JM, Milosavljevic MZ, Protrka ZM, et al. Gestational choriocarcinoma of the cervix. Arch Iran References Med. 2014;17(11):783-85.

3. Erbil K, Orkur C, Ali K, Irfan B. Primary tubal choriocarcinoma presented as ruptured ectopic gestation. J Clin Diagn Res. 2015;9(9):QD17-18.

4. Jurkovic D, Hillaby K, Woelfer B, Lawrence A, Salim R, Elson CJ. First trimester diagnosis and management of pregnancies implanted into the lower uterine caesarian section scar. Ultrasound Obstet Gynecol. 2003;21:220-7.

5. Qian ZD, Zhu XM. Caesarean scar choriocarcinoma: a case report and review of the literature. Eur J Med Res. 2014;19:25.

6. Antonella V, Alessandra C, Leonardo R, Gennaro C, Ettore C. Sonographic and Power Doppler Evaluation of an invasive mole located in a Cesarean Scar Pregnancy. 2016;35(7):1608-12.

7. Sherer DM, Dalloul M, Cho Y, Mylvaganam SR, Adeyemo I, Zinn HL, et al. Spontaneous first trimester perforation of the uterus following Cesarean scar pregnancy choriocarcinoma. Ultrasound Obstet Gynecol. 2016;47(4):519-21.

8. Bekci T. Caesarean Scar Choriocarcinoma: Ultrasound and Magnetic Resonance Imaging Findings, Journal of the Belgian Society of Radiology. 2016;100(1):46,1-3.

9. Litwicka, Katarzyna, Greco, Ermanno. Caesarean scar pregnancy: a review of management options; Current Opinion in Obstetrics and Gynecology Dec 2013;25(6):456-61.

10. Olaniyan OBJ, Momoh AF. Negative urine hCG in choriocarcinoma: International Journal of Gynecology and Obstetrics. 2007;98,(1):59-60.

11. Mehra R, Huria A, Gupta P, Mohan H. Choriocarcinoma with negative urinary and serum beta human chorionic gonadotropin Indian $\mathrm{J}$ Med Sci. 2005;59(12):538-41.

12. Siew-Fei NGU, Karen KL. Management of Chemo resistant and quiescent gestational trophoblastic disease. Curr Obstet Gynecol Rep. 2014;3(1):84-90.

Cite this article as: Sumangala S, Pillai MM, Chellamma N, Raji L. Choriocarcinoma following scar pregnancy: a case report. Int J Reprod Contracept Obstet Gynecol 2016;5:4519-21. 